\title{
Oxygen diffusion in Gd-doped mixed oxides
}

Galvin, C.O.T; Cooper, M.W.D.; Rushton, Michael; Grimes, R.W.

\section{Journal of Nuclear Materials}

\author{
DOI: \\ 10.1016/j.jnucmat.2017.10.036
}

Published: 01/01/2018

Peer reviewed version

Cyswllt i'r cyhoeddiad / Link to publication

Dyfyniad o'r fersiwn a gyhoeddwyd / Citation for published version (APA):

Galvin, C. O. T., Cooper, M. W. D., Rushton, M., \& Grimes, R. W. (2018). Oxygen diffusion in Gd-doped mixed oxides. Journal of Nuclear Materials, 300-306.

https://doi.org/10.1016/j.jnucmat.2017.10.036

\footnotetext{
Hawliau Cyffredinol / General rights

Copyright and moral rights for the publications made accessible in the public portal are retained by the authors and/or other copyright owners and it is a condition of accessing publications that users recognise and abide by the legal requirements associated with these rights.

- Users may download and print one copy of any publication from the public portal for the purpose of private study or research.

- You may not further distribute the material or use it for any profit-making activity or commercial gain

- You may freely distribute the URL identifying the publication in the public portal ?
}

Take down policy

If you believe that this document breaches copyright please contact us providing details, and we will remove access to the work immediately and investigate your claim. 


\title{
Oxygen Diffusion in Gd-doped Mixed Oxides
}

\author{
C. O. T. Galvin ${ }^{\mathrm{a}}$, M. W. D. Cooper ${ }^{\mathrm{b}}$, M. J. D. Rushton ${ }^{\mathrm{a}}$, R. W. Grimes ${ }^{\mathrm{a}}$ \\ ${ }^{a}$ Department of Materials, Imperial College London, London, SW7 2AZ, UK \\ ${ }^{b}$ Materials Science and Technology Division, Los Alamos National Laboratory, P.O. Box 1663, Los Alamos, New Mexico
} 87545, USA

\begin{abstract}
Molecular dynamics simulations have been performed to investigate oxygen transport in $\left(\mathrm{U}_{\mathrm{x}} \mathrm{Pu}_{\mathrm{x}-1}\right)_{0.95} \mathrm{Gd}_{0.05} \mathrm{O}_{1.975},\left(\mathrm{U}_{\mathrm{x}} \mathrm{Th}_{\mathrm{x}-1}\right)_{0.95} \mathrm{Gd}_{0.05} \mathrm{O}_{1.975}$ and $\left(\mathrm{Pu}_{\mathrm{x}} \mathrm{Th}_{\mathrm{x}-1}\right)_{0.95} \mathrm{Gd}_{0.05} \mathrm{O}_{1.975}$ between 1000-3200 K. Oxygen diffusivity and corresponding activation energies are examined and compared to values for the undoped $\left(\mathrm{U}_{\mathrm{x}} \mathrm{Pu}_{\mathrm{x}-1}\right) \mathrm{O}_{2},\left(\mathrm{U}_{\mathrm{x}} T \mathrm{~T}_{\mathrm{x}-1}\right) \mathrm{O}_{2}$ and $\left(\mathrm{Pu}_{\mathrm{x}} T \mathrm{Th}_{\mathrm{x}-1}\right) \mathrm{O}_{2}$ systems where compositions between end members display enhanced diffusivity. Below the superionic transition oxygen diffusivity for the Gd doped systems is orders of magnitude greater compared to their undoped counterparts. However, enhanced diffusivity for doped mixed actinide cation compositions is not observed compared to doped end members. Changes in activation energy suggest changes in diffusion regime, which correspond to the creation of thermally activated oxygen defects.
\end{abstract}

\section{Introduction}

$\mathrm{UO}_{2}$ is the primary conventional fuel used in most nuclear reactors. It can, however, be mixed with other actinide oxides such as $\mathrm{PuO}_{2}$ and $\mathrm{ThO}_{2}$ to make mixed oxide fuel (MOX). Transmutation of $\mathrm{U}^{238}$ to $\mathrm{Pu}^{239}$ during reactor operation means that fuel effectively becomes a $(\mathrm{U}, \mathrm{Pu}) \mathrm{O}_{2}$ solid solution. $(\mathrm{U}, \mathrm{Pu}) \mathrm{O}_{2}$, as a fresh fuel, is also a viable route for Pu burning [1]. There is also a growing interest in using Th based nuclear fuel due to its abundance and promising properties [2,3]. However, while Th is fertile it is non-fissile so it needs to be blended with a fissile isotope such as $\mathrm{U}^{235}$ or $\mathrm{Pu}^{239}$ to make $(\mathrm{U}, \mathrm{Th}) \mathrm{O}_{2}$ or $(\mathrm{Th}, \mathrm{Pu}) \mathrm{O}_{2}$. There are $\sim 40$ reactors worldwide licensed to use MOX [4]. Understanding how the compositions of these mixed oxides affect their thermophysical properties is of importance for safe and efficient reactor operation and a substantial body of experimental and modelling work is being carried out to investigate these properties [5-22].

Burnable poisons are used in nuclear fuels as neutron absorbers to produce a more level distribution of power, geometrically and temporally in the reactor core, reducing the necessity for a large control system. The gadolinium isotopes $\mathrm{Gd}^{155}$ and $\mathrm{Gd}^{157}$ are commonly chosen as dopants due to their large neutron cross sections and because they are soluble on an atomic scale in the ceramic fuel pellets (forming a solid solution) [23-28]. The amount of $\mathrm{Gd}_{2} \mathrm{O}_{3}$ added as a burnable absorber varies, from 1-1.5 $\mathrm{wt} \%$ in boiling water reactor fuel to 6-10 $\mathrm{wt} \% \mathrm{Gd}_{2} \mathrm{O}_{3}$ in pressurised water reactor fuel $[29,30]$. Even if $\mathrm{Gd}$ is not added during fuel manufacturing, Gd will be introduced into the fuel during reactor operation as it is formed as a fission product

Email address: r.grimes@imperial.ac.uk (R. W. Grimes) 
(although this will be of a lower concentration). The simulations conducted in this paper have a Gd content of $\sim 3 \mathrm{wt} \%$.

Previous experimental studies have found that oxygen self diffusion in $\mathrm{UO}_{2}$ containing $\mathrm{Y}_{2} \mathrm{O}_{3}$ is faster and occurs with a lower activation enthalpy than in pure $\mathrm{UO}_{2}[31,32]$. Similarly, work on the electrical conductivity of $\mathrm{ThO}_{2}-\mathrm{Y}_{2} \mathrm{O}_{3}$ solid solutions show that the incorporation of $\mathrm{Y}^{3+}$ increase the concentration of oxygen vacancies and as a consequence oxygen diffusion is more rapid [33]. Addition of other trivalent ions such as $\mathrm{Gd}^{3+}$ ions may therefore also increase the concentration of oxygen vacancies, leading to oxygen diffusivity in nuclear fuels. This would follow if $\mathrm{Gd}^{3+}$ ions substitute for tetravalent actinide ions with charge compensation provided by oxygen vacancies:

$$
\mathrm{Gd}_{2} \mathrm{O}_{3}+2 \mathrm{M}_{\mathrm{M}}^{\times}+\mathrm{O}_{\mathrm{O}}^{\times} \longrightarrow 2 \mathrm{Gd}_{\mathrm{M}}^{\prime}+\mathrm{V}_{\mathrm{O}}^{\bullet \bullet}+2 \mathrm{MO}_{2}
$$

Previous work has focused on the thermophysical properties and oxygen transport of $(\mathrm{U}, \mathrm{Pu}) \mathrm{O}_{2}$, $(\mathrm{U}, \mathrm{Th}) \mathrm{O}_{2}$ and $(\mathrm{Th}, \mathrm{Pu}) \mathrm{O}_{2}[9-14,16,20]$ and how they are changed as a consequence of mixed actinide composition. For $\mathrm{UO}_{2}, \mathrm{PuO}_{2}, \mathrm{ThO}_{2}$ and MOX $[9,10,13,18,19,34,35]$ there is a deviation from linear thermal expansion and a classical Debye description of the constant pressure specific heat above $1300 \mathrm{~K}$. Similar effects were reported in urania-gadolinia where a dramatic increase in specific heat occurs at elevated temperatures [36]. Krishnan et al. [36] suggest that the increase in heat capacity might be due "to predominant contribution of formation of Frenkel pairs of oxygen" resulting from the $\mathrm{UO}_{2}$ being doped with aliovalent cations. However, the specific heat was studied between $300-900 \mathrm{~K}$ and for $\mathrm{UO}_{2}$ it is suggested the lattice contribution with a small contribution of $5 \mathrm{f}$ electron excitations can account for the increase in specific heat over this temperature range [37, 38]. For $\mathrm{UO}_{2}, \mathrm{PuO}_{2}, \mathrm{ThO}_{2}$ and $\mathrm{MOX}$ a superionic transition [39] is known to occur at temperatures greater than $\sim 2000 \mathrm{~K}$. Further, X-ray and neutron diffraction experiments by Ruello et al. [40] provide evidence that an electronic disorder can be attributed to the deviation from Debye behaviour at $1300 \mathrm{~K}$.

Using molecular dynamics (MD) this paper investigates oxygen transport in Gd doped $(\mathrm{U}, \mathrm{Pu}) \mathrm{O}_{2}$, $(\mathrm{U}, \mathrm{Th}) \mathrm{O}_{2}$ and $(\mathrm{Pu}, \mathrm{Th}) \mathrm{O}_{2}$, between 1000-3200 K. Comparisons are drawn with previous work carried out on oxygen transport in the undoped systems $[9,10,13]$.

\section{Methodology}

\subsection{Potential model}

MD simulations are carried out using the large-scale atomic/molecular massively parallel simulator (LAMMPS) [41] where the interatomic forces were described using the Cooper, Rushton and Grimes (CRG) [42] potential ${ }^{1}$. This combines a pair potential with a many body contribution using the embedded atom method of Daw and Baskes [43]. The Gd-O parameters employed in this study have been used successfully to model oxygen diffusion in strained Gd doped ceria [44]. The CRG approach accurately reproduces the experimentally determined thermal expansion, elastic constants and melting points of $\mathrm{UO}_{2}, \mathrm{PuO}_{2}$ and $\mathrm{ThO}_{2}$ [17]. This is

\footnotetext{
${ }^{1}$ Potential form, potential parameters and downloadable example files can be found at http://abulafia.mt.ic.ac.uk/potentials
} 
important as to describe oxygen transport properties the potential must describe the thermal expansion accurately [44]. Moreover, the CRG potential approach has been used previously to investigate oxygen transport in $\operatorname{MOX}[9,10,13,45]$.

\subsection{Calculation details}

The simulation cells were constructed by repeating the $\mathrm{M}_{4} \mathrm{O}_{8}$ cubic fluorite unit cell 10 times in the three orthogonal directions. For each MOX five compositions were investigated: the two end members, a $25 \%-75 \%, 50 \%-50 \%$, and a $75 \%-25 \%$. For each of the mixed actinide cells, 10 distinct structures, each with actinide cation positions assigned randomly were created for each composition. For each composition, averages of oxygen diffusivity over the 10 structures were taken. Simulations were performed for $\left(\mathrm{U}_{\mathrm{x}} \mathrm{Pu}_{\mathrm{x}-1}\right) \mathrm{O}_{2},\left(\mathrm{U}_{\mathrm{x}} T \mathrm{Th}_{\mathrm{x}-1}\right) \mathrm{O}_{2}$, $\left(\mathrm{Th}_{\mathrm{x}} \mathrm{Pu}_{\mathrm{x}-1}\right) \mathrm{O}_{2}$ each with $5 \%$ of the tetravalent cations randomly replaced with $\mathrm{Gd}$ (i.e replacing 200 actinide cations with $\mathrm{Gd}^{3+}$ ions). For the system to be charge neutral 100 random oxygen vacancies were introduced ( $\mathrm{O}$ vacancies were used rather than cation interstitials [23]). Conjugate gradient static energy minimization, with the system size allowed to change, was used to allow each of the structures to find its local energy minimum. Following this, an MD run with an isobaric-isothermal (NPT) ensemble was carried out for 30 ps. The first 10 ps was used to bring the system up to the desired temperature and then the system was allowed to equilibrate at the target temperature for 20 ps. An average was taken over the last $10 \mathrm{ps}$ and the systems lattice parameter was changed to the obtained average. The simulation was then run for a microcanonical (NVE) ensemble for $1 \mathrm{~ns}$. For all MD simulations Nosé-Hoover barostat and thermostat relaxation times of 0.5 and 0.1 ps were used respectively. An MD timestep of $1 \mathrm{fs}$ was used throughout. Subsequently, the oxygen mean squared displacement (MSD), $\left\langle R_{O}^{2}\right\rangle$, was calculated and the diffusivity, $D$, was determined using equation 2 ,

$$
D=\frac{\left\langle R_{O}^{2}\right\rangle}{2 d t}
$$

where $t$ and $d$ are the time and the number of dimensions (here $\mathrm{d}=3$ ) over which diffusion was calculated respectively. For all simulations in this paper, stoichiometry remains constant as a function of temperature.

\section{Results and Discussion}

\subsection{Oxygen Diffusion}

Figures 1,2 and 3 depict the oxygen diffusivity, D, plotted on a log scale as a function of $1 / \mathrm{T}$ for different actinide compositions of the Gd doped $(\mathrm{U}, \mathrm{Pu}) \mathrm{O}_{2},(\mathrm{U}, \mathrm{Th}) \mathrm{O}_{2}$ and $(\mathrm{Pu}, \mathrm{Th}) \mathrm{O}_{2}$ systems. Therefore, an Arrhenius relationship is being tested where the activation energy for oxygen diffusion $\left(\mathrm{H}_{\mathrm{a}}\right)$ is proportional to the gradient of the graph:

$$
D=D_{0} \exp \left(\frac{-H_{a}}{k_{B} T}\right)
$$

where $\mathrm{D}_{0}$ is the pre-exponential, $\mathrm{k}_{\mathrm{B}}$ is the Boltzmann constant and $\mathrm{T}$ is the temperature. The error bars in all the figures indicate the standard deviation.

Comparing the oxygen diffusivities of the pure $\mathrm{UO}_{2}, \mathrm{PuO}_{2}$ and $\mathrm{ThO}_{2}$ systems with the $\mathrm{Gd}$ doped systems (see figure 4) it can be seen that for the doped systems, at lower temperatures, the oxygen diffusivity is raised by orders of magnitude. This occurs until contributions from 
thermally activated (intrinsic) oxygen defects exceeds that of the doped (extrinsic) defects, corresponding to an increased gradient (discussed later). Above this temperature and into the superionic transition the doped and undoped cases are the same (see Appendix). Turning now to the Gd doped MOX systems, each of the oxygen diffusivity graphs shown in figures 1,2 and 3 depict three regions of constant gradient, suggesting three different diffusion regimes. It has been shown previously $[9,10,13]$ for the undoped $\left(\mathrm{U}_{\mathrm{x}} \mathrm{Pu}_{\mathrm{x}-1}\right) \mathrm{O}_{2},\left(\mathrm{U}_{\mathrm{x}} \mathrm{Th}_{\mathrm{x}-1}\right) \mathrm{O}_{2},\left(\mathrm{Th}_{\mathrm{x}} \mathrm{Pu}_{\mathrm{x}-1}\right) \mathrm{O}_{2}$ systems that the MD data is consistent with two diffusion regimes, with the change in diffusion regime occurring at high temperature due to a superionic transition.

Figure 1 shows that for $\mathrm{Gd}$ doped $\left(\mathrm{U}_{\mathrm{x}} \mathrm{Pu}_{\mathrm{x}-1}\right) \mathrm{O}_{2},(\mathrm{Pu}, \mathrm{Gd}) \mathrm{O}_{2}$ exhibits the highest oxygen diffusivity while $(\mathrm{U}, \mathrm{Gd}) \mathrm{O}_{2}$ has the lowest (i.e the end members have the highest and lowest values of oxygen diffusion and the values for the MOX compositions lie in-between). Further, small additions of $\mathrm{Pu}$ to $(\mathrm{U}, \mathrm{Gd}) \mathrm{O}_{2}$ have little effect on the oxygen diffusivity. This contrasts to the data presented in figures 2 and 3. In these, for the low temperature regime, small additions of $\mathrm{U}$ or $\mathrm{Pu}$ to $(\mathrm{Th}, \mathrm{Gd}) \mathrm{O}_{2}$ cause the oxygen diffusivity to be even lower than pure $\mathrm{ThO}_{2}$.

At low temperatures each doped system has a low oxygen migration activation energy as the system has an oxygen vacancy concentration dominated by Gd doping, which is independent of temperature (see figures 5, 6 and 7). Therefore, only the hopping energy is included in the activation energy, not the formation energy for oxygen vacancies. As the temperature increases the thermal equilibrium concentration of oxygen vacancies begins to overtake the fixed extrinsic concentration. The oxygen vacancy concentration is now temperature dependent. Thus, the oxygen vacancy formation energy (which is large compared to the hopping energy) and the hopping energy both contribute to the activation energy. Consequently the Arrhenius plots (figures1, 2 and 3) show diffusion to be more heavily dependent on temperature so that the middle region exhibits a steep gradient. At higher temperatures above the superionic transition, no more oxygen defects can be formed. There is, therefore, no longer a temperature dependent change in defect concentration. There is still a hopping energy associated with the movement of oxygen ions, however, the formation energy no longer contributes and the activation energy is once again small (see figures 5, 6 and 7). Although similar, the hopping energy is not exactly the same at high temperature as at low temperature because the lattice has changed due to the superionic transition (i.e. the oxygen sublattice has become completely disordered after the superionic transition).

\subsection{Compositional Dependence of Diffusion}

The diffusivity predictions are now shown as a function of actinide composition (figure 8) and compared with previous data for undoped MOX systems (figure 9). It was predicted previously that enhanced oxygen diffusivity occurs for $\left(\mathrm{U}_{\mathrm{x}} \mathrm{Pu}_{\mathrm{x}-1}\right),\left(\mathrm{U}_{\mathrm{x}} T \mathrm{~h}_{\mathrm{x}-1}\right)$ and $\left(\mathrm{Th}_{\mathrm{x}} \mathrm{Pu}_{\mathrm{x}-1}\right)$ at temperatures under the superionic transition [13] (i.e. diffusivity is greater than just a linear interpolation from the end members). Further, this enhanced oxygen diffusivity is greater in the U-Th and $\mathrm{Pu}$-Th cases due to the greater lattice parameter mismatch. It has been suggested that the oxygen defect formation enthalpies contribute to this enhanced diffusion $[9,10,13])$. In the mixed compositions oxygen vacancy formation energies are lower and thus concentrations are higher. For the same Gd doped MOX systems however, enhanced oxygen diffusivity is not observed. This is because oxygen defect concentrations are already much higher due to the requirement to charge compensate for the Gd dopant concentration (as mentioned in section 2.2). These bring about oxygen diffusivities higher by orders of magnitude at lower temperatures (as seen by comparing figures 8 and 9). 
As the temperature reaches the superionic region there is very little difference between oxygen diffusivities of Gd doped and undoped MOX systems (figures 8 and 9). This is expected as the oxygen vacancy concentration becomes temperature independant within the superionic region as the systems become saturated with oxygen defects [9]. Therefore, the hopping energy is the dominant component in oxygen diffusion and the effect of the vacancy enhanced diffusivity observed at lower temperatures in figure 9, for undoped MOX, no longer contributes. The current results on the Gd-doped MOX therefore indicate that a mixed cation lattice has only a small impact on the oxygen hopping energy compared to the impact on the oxygen defect formation enthalpies.

\section{Conclusions}

MD simulations were performed to examine the effect of oxygen transport in different mixed actinide compositions of $\sim 3 \mathrm{wt} \% \mathrm{Gd}$ doped $\left(\mathrm{U}_{\mathrm{x}} \mathrm{Pu}_{\mathrm{x}-1}\right) \mathrm{O}_{2},\left(\mathrm{U}_{\mathrm{x}} \mathrm{Th}_{\mathrm{x}-1}\right) \mathrm{O}_{2}$ and $\left(\mathrm{Pu}_{\mathrm{x}} \mathrm{Th}_{\mathrm{x}-1}\right) \mathrm{O}_{2}$. Results were compared to those for the undoped systems. Three different gradients, which were identified on an Arrhenius plot suggesting three different diffusion regimes for oxygen in the Gd doped systems while only two gradients are seen for undoped systems. The change in gradient at high temperatures (above $2700 \mathrm{~K}$ ) can be associated with the superionic transition $[9,10,13]$. Below the superionic transition temperature there was a clear difference (by orders of magnitude) when comparing the oxygen diffusivity of the Gd systems against the undoped systems. The Gd doped systems have much higher oxygen diffusivity compared to their undoped counterparts. This is a consequence of the pre-existing oxygen vacancies in the doped system necessary for charge balance, when $\mathrm{Gd}^{3+}$ ions replace tetravalent actinide cations. For Gd doped systems, this is the origin of the different gradients of the oxygen diffusivity. At low temperatures there is a low activation energy associated with a hopping energy of the oxygen atom as oxygen vacancy formation does not contribute. For temperatures between 2000-2500 K the activation energy increases as it includes both the hopping energy and the thermally activated energy to create oxygen vacancy defects via Frenkel disorder. Above $\sim 2700 \mathrm{~K}$ the superionic oxygen sublattice is saturated with defects, therefore the Frenkel pair formation energy no longer contributes and there is a decrease in the activation energy in line with that of the undoped system. Thus, the enhancement in oxygen diffusivity in undoped MOX compared to the pure end members (predicted previously $[9,10,13]$ ) is not in operation even if the systems are doped with $\sim 3 \mathrm{wt} \% \mathrm{Gd}$. This indicates that previous conclusions regarding enhanced oxygen diffusivity in MOX are not relevant if Gd is incorporated as a burnable poison (or presumably if trivalent cations are formed by other mechanisms). Nevertheless, for each of the Gd doped systems the oxygen diffusivity is raised by at least an order of magnitude compared to the undoped systems. In this work however, the charge compensation mechanism is via oxygen vacancy creation. Under certain oxidising conditions, the $\mathrm{U}^{5+}$ ion may be the preferred charge compensation mechanism for Gd, in which case further MD studies should be carried out to determine if oxygen diffusivity is enhanced in MOX systems under such conditions.

\section{Acknowledgements}

This work was sponsored by the U.S. Department of Energy, the Office of Nuclear Energy, through the Consortium for Advanced Simulations of Light Water Reactors (CASL) and Nuclear Energy Advanced Modeling and Simulation (NEAMS) programs. Computational resources were provided by the Imperial College High Performance Computing Service and Los Alamos National Laboratory. The Los Alamos National Laboratory, an affirmative action/equal opportunity employer, is operated by the Los Alamos National Security, LLC, for the National 
Nuclear Security Administration of the US Department of Energy under Contract No. DEAC52-06NA25396.

\section{Appendix}

Figure 10 shows the oxygen diffusivity as a function of temperature for different concentrations of $\mathrm{Gd}$ (and therefore oxygen vacancies) in $\mathrm{UO}_{2}$. At lower temperatures there is a shift in oxygen diffusivity dependent on the fixed extrinsic defect concentration between the $\left(\mathrm{U}_{0.99} \mathrm{Gd}_{0.01}\right) \mathrm{O}_{1.995}$ and $\left(\mathrm{U}_{0.95} \mathrm{Gd}_{0.05}\right) \mathrm{O}_{1.975}$ compositions. There are no extrinsic oxygen vacancies (due to no dopants) in $\mathrm{UO}_{2}$ and as a consequence, at low temperatures, the oxygen diffusivity values are much lower compared to doped $\mathrm{UO}_{2}$. As the temperature is increased $(>2000 \mathrm{~K})$ the dominant term becomes the thermally activated (intrinsic) oxygen defects and the diffusivity values for all the compositions are the same. The simulation conducted to calculate the oxygen diffusivity values for $\left(\mathrm{U}_{0.99} \mathrm{Gd}_{0.01}\right) \mathrm{O}_{1.995}$ is the same as described in section 2.2. The $\left(\mathrm{U}_{0.99} \mathrm{Gd}_{0.01}\right) \mathrm{O}_{1.995}$ structure was created by repeating the $\mathrm{M}_{4} \mathrm{O}_{8}$ fluorite unit cell 22 times in three orthogonal directions compared to 10 as described in section 2.2. This allowed one simulation to be carried out as opposed to taking an average of 10 simulations on 10 distinct structures. $1 \%$ of the tetravalent cations were randomly replaced with Gd (i.e replacing 426 $\mathrm{UO}_{2}$ cations with $\mathrm{Gd}^{3+}$ ions) and 213 random oxygen vacancies were introduced to maintain charge neutrality.

\section{References}

[1] R. C. Ewing Ceramic matrices for plutonium disposition. Prog. Nucl. Energy, 49(8):635-643 (2007).

[2] International Atomic Energy Agency. Thorium fuel cycle-Potential benefits and challenges. Technical Document, 1450 (2005).

[3] A. F. Stephen, G. T. Parks, W. J. Nuttall, C. Boxall, and R. W. Grimes. Thorium fuel has risks. Nature, 492:31-33 (2012).

[4] The Royal Society. Strategy options for the UK's separated plutonium. Policy Document (2009).

[5] K. Bakker, E. H. P.Cordfunke, R. J. M. Konings and R. P. C. Schram Critical evaluation of the thermal properties of Th02 and Th1-yUy02 and a survey of the literature data on Th1-yPuy02. J. Nucl. Mater., 2501(1):1-12 (1997).

[6] S. Dash, S. C. Parida, Z. Singh, B. K. Sen and V. Venugopal. Thermodynamic investigations of ThO2-UO2 solid solutions. J. Nucl. Mater., 393(2):267-281 (2009).

[7] R. Kandan, R. Babu, P. Manikandan, R. V. Krishnan and K. Nagarajan. Calorimetric measurements on (U,Th)O2 solid solutions. J. Nucl. Mater., 384(3):231-235 (2009).

[8] O. S. Vălu, O. Beneš, R. J. M. Konings and H. Hein. The high temperature heat capacity of the (Th,Pu)O2 system. J. Chem. Thermodyn., 68:122-127 (2014).

[9] M. W. D. Cooper, S. T. Murphy, P. C. M. Fossati, M. J. D. Rushton, and R. W. Grimes. Thermophysical and anion diffusion properties of $(\mathrm{Ux}, \mathrm{Th} 1-\mathrm{x}) \mathrm{O} 2$. Proc. R. Soc. A Math. Phys. Eng. Sci., 470(2171):20140427-20140427 (2014). 
[10] M. W. D. Cooper, S. T. Murphy, M. J. D. Rushton, and R. W. Grimes. Thermophysical properties and oxygen transport in the (Ux,Pu1-x)O2 lattice. J. Nucl. Mater., 461:206-214 (2015).

[11] S. I. Potashnikov, A. S. Boyarchenkov, K. A. Nekrasov, and A. Ya. Kupryazhkin. Highprecision molecular dynamics simulation of UO2-PuO2: Pair potentials comparison in UO2. J. Nucl. Mater., 419(1-3):217-225 (2011).

[12] S. I. Potashnikov, A. S. Boyarchenkov, K. A. Nekrasov, and A. Ya. Kupryazhkin. Highprecision molecular dynamics simulation of UO2-PuO2: Anion self-diffusion in UO2. J. Nucl. Mater., 433(1-3):215-226 (2013).

[13] C. O. T. Galvin, M. W. D. Cooper, M. J. D. Rushton, and R. W. Grimes. Thermophysical properties and oxygen transport in (Thx,Pu1-x)O2. Sci. Rep., 6:36024 (2016).

[14] P. S. Ghosh, P. S. Somayajulu, K. Krishnan, N. Pathak, A. Arya, and G. K. Dey. Thermal expansion and thermal conductivity of $(\mathrm{Th}, \mathrm{U}) \mathrm{O} 2$ mixed oxides:A molecular dynamics and experimental study. J. Alloys Compd., 650:165-177 (2015).

[15] M. W. D. Cooper, S. C. Middleburgh and R. W. Grimes. Modelling the thermal conductivity of (UxTh1-x)O2 and (UxPu1-x)O2 J. Nucl. Mater., 466:29-35 (2015).

[16] D. S. Aidhy. Oxygen diffusion in ThO $2-\mathrm{CeO} 2$ and ThO $2-\mathrm{UO} 2$ solid solutions from atomistic calculations. Phys. Chem. Chem. Phys., 18(22):15019-15024 (2016).

[17] P. S. Ghosh, N. Kuganathan, C. O. T. Galvin, A. Arya, G. K. Dey, B. K. Dutta, and R. W. Grimes. Melting behavior of (Th,U)O2 and (Th,Pu)O2 mixed oxides. J. Nucl. Mater., 479:112-122 (2016).

[18] J. -J. Ma, J. Zheng, M. -J. Wan, J. -G. Du, J. Yang, and G. Jiang. Molecular dynamical study of physical properties of (U0.75Pu0.25)O2-x. J. Nucl. Mater., 452(1-3):230-234 (2014).

[19] J. -J. Ma, J. -G. Du, M. -J. Wan, and G. Jiang. Molecular dynamics study on thermal properties of ThO2 doped with $\mathrm{U}$ and $\mathrm{Pu}$ in high temperature range. J. Alloys Compd., 627:476482 (2015).

[20] T. Arima, S. Yamasaki, Y. Inagaki, and K. Idemitsu. Evaluation of thermal conductivity of hypostoichiometric $(\mathrm{U}, \mathrm{Pu}) \mathrm{O} 2$-x solid solution by molecular dynamics simulation at temperatures up to 2000K. J. Alloys Compd., 415(1-2):43-50 (2006).

[21] R. L. Gibby The effect of plutonium content on the thermal conductivity of $(\mathrm{U}, \mathrm{Pu}) \mathrm{O} 2$ solid solutions. J. Nucl. Mater., 38(2):163-177 (1971).

[22] W. L. Lyon and W. E. Baily. The solid-liquid phase diagram for the UO2-PuO2 system. J. Nucl. Mater., 22(3):332-339 (1967).

[23] K. Kapoor, S. V. Ramana Rao, Sheela, T. Sanyal, and A. Singh. Study on solid solubility of Gd in UO2 using X-ray diffraction. J. Nucl. Mater., 321(2-3):331-334 (2003).

[24] R. J. Beals and J. H. Handwerk. Solid Solutions in the System Urania-Rare-Earth Oxides: I, UO2-GdO1.5,. J. Am. Ceram. Soc., 48(5):271-274 (1965).

[25] K. Une and M. Oguma. Thermodynamic properties of nonstoichiometric urania-gadolinia solid solutions in the temperature range $700-1100^{\circ}$ C. J. Nucl. Mater., 110(2-3):215-222 (1982). 
[26] Hideaki Inaba, Keiji Naito, and Masaomi Oguma. Heat capacity measurement of U1yGdyO2 $(0.00<=\mathrm{y}<=0.142)$ from 310 to $1500 \mathrm{~K}$. J. Nucl. Mater., 149(3):341-348, aug 1987.

[27] Z. Tianshu. Ionic conductivity in the $\mathrm{CeO} 2-\mathrm{Gd} 2 \mathrm{O} 3$ system $(0.05<=\mathrm{Gd} / \mathrm{Ce}<=0.4)$ prepared by oxalate coprecipitation. Solid State Ionics, 148(3-4):567-573 (2002).

[28] A. Baena,T. Cardinaels, B. Vos, K. Binnemans and M. Verwerft. Synthesis of UO2 and ThO2 doped with Gd2O3. J. Nucl. Mater., 461 271-281 (2015).

[29] IAEA. Characteristics and Use of Urania-Gadolinia Fuels. 1-191 (1995).

[30] B. Palanki. Fabrication of UO2-Gd2O3 Fuel Pellets. J. Mater. Sci. Chem. Eng., 4(2):8-21, (2016).

[31] Westinghouse Electric Corporation, U.S. Atomic Energy Commission and Bettis Atomic Power Laboratory. Technical progress report, Pressurized Water Reactor (PWR) Project April/June (WAPD-MRP-86). (1960)

[32] Westinghouse Electric Corporation, U.S. Atomic Energy Commission and Bettis Atomic Power Laboratory. Technical progress report, Pressurized Water Reactor (PWR) Project October/December (WAPD-MRP-89). (1960)

[33] E. C. Subbarao, P. H. Sutter and J. Hrizo. Defect Structure and Electrical Conductivity of ThO2-Y2O3 Solid Solutions. J. Am. Ceram. Soc., 48(9):443-446 (1965).

[34] S. I. Potashnikov, A. S. Boyarchenkov, K. A. Nekrasov, and A. Ya. Kupryazhkin. Highprecision molecular dynamics simulation of $\mathrm{UO} 2-\mathrm{PuO} 2$ : superionic transition in uranium dioxide. J. Nucl. Mater., 415(2):217-221 (2011).

[35] S. O. Vălu, O. Beneš, D. Manara, R. J. M. Konings, M. W. D. Cooper, R. W. Grimes, and C. Guéneau. The high-temperature heat capacity of the $(\mathrm{Th}, \mathrm{U}) \mathrm{O} 2$ and $(\mathrm{U}, \mathrm{Pu}) \mathrm{O} 2$ solid solutions. J. Nucl. Mater., 484:1-6 (2017).

[36] R. Venkata Krishnan, G. Panneerselvam, P. Manikandan, M. P. Antony, and K. Nagarajan. Heat Capacity and Thermal Expansion of Uranium-Gadolinium Mixed Oxides. J. Nucl. Radiochem. Sci., 10(1):19-26 (2009).

[37] C. Guéneau, A. Chartier and L. Van Brutzel. Thermodynamic and Thermophysical Properties of the Actinide Oxides. Compr. Nucl. Mater., 2:21-59 (2012).

[38] R. J. M Konings, L. R. Morss and J. Fuger Thermodynamic properties of actinides and actinide compounds. Chem. Actin. Trans. Elem., 2113-2224 (2006).

[39] A. Annamareddy and J. Eapen. Disordering and dynamic self-organization in stoichiometric UO2 at high temperatures. J. Nucl. Mater., 483:132-141 (2017).

[40] P. Ruello, L. Desgranges, G. Baldinozzi, G.Calvarin, T. Hansen, G. Petot-Ervas and C. Petot. Heat capacity anomaly in UO2 in the vicinity of 1300K: an improved description based on high resolution X-ray and neutron powder diffraction studies. J. Phys. Chem. Solids, 66(5):823-831 (2005).

[41] S. Plimpton. Fast Parallel Algorithms for Short-Range Molecular Dynamics (1995). 
[42] M. W. D. Cooper, M. J. D. Rushton, and R. W. Grimes. A many-body potential approach to modelling the thermomechanical properties of actinide oxides. J. Phys. Condens. Matter, 26(10):105401 (2014).

[43] M. S. Daw and M. I. Baskes. Embedded-atom method: Derivation and application to impurities, surfaces, and other defects in metals. Phys. Rev. B, 29(12):6443 (1984).

[44] M. J. D. Rushton and A. Chroneos. Impact of uniaxial strain and doping on oxygen diffusion in CeO2. Sci. Rep., 4:6068 (2014).

[45] M. W. D. Cooper, R. W. Grimes, M. E. Fitzpatrick, and A. Chroneos. Modeling oxygen self-diffusion in UO2 under pressure. Solid State Ionics, 282:26-30 (2015). 


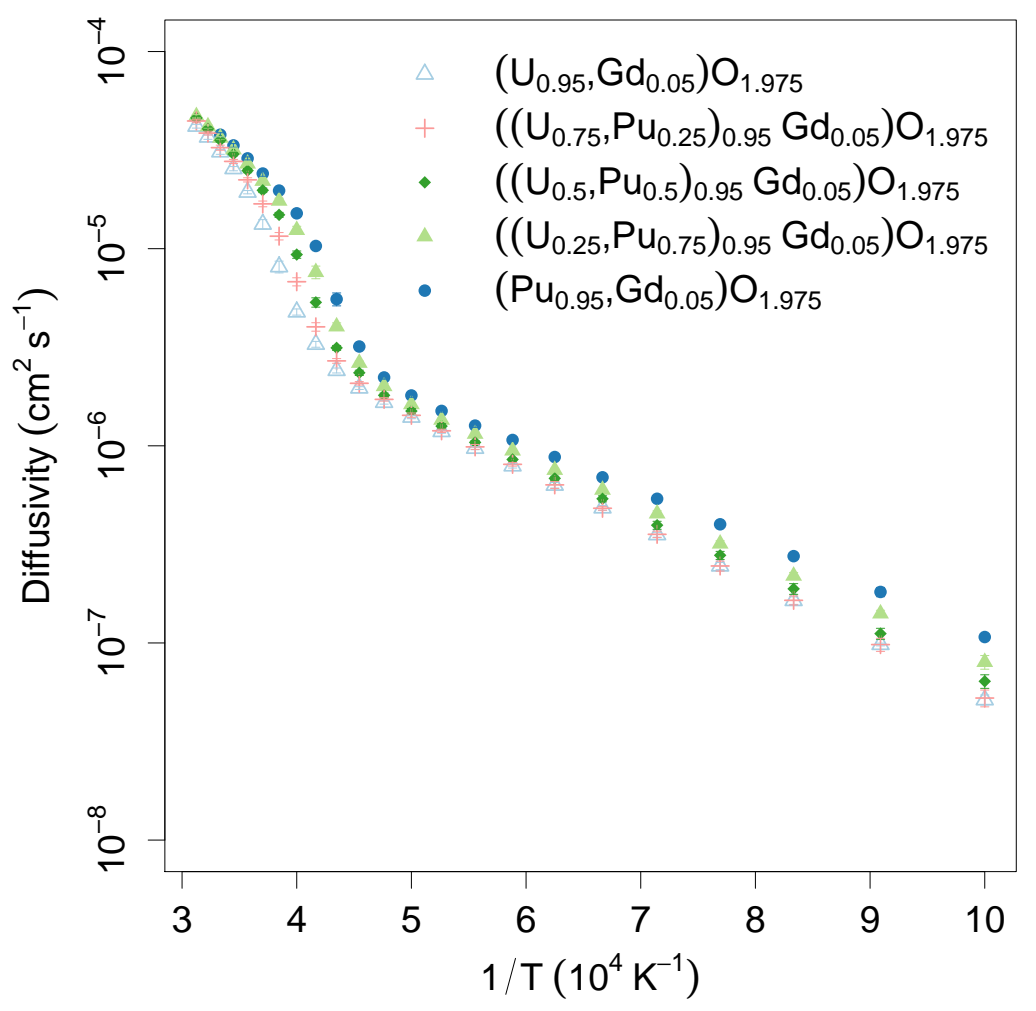

Figure 1: Oxygen diffusivity as a function of temperature for different compositions of $\left(\mathrm{U}_{\mathrm{X}} \mathrm{Pu}_{\mathrm{x}-1}\right)_{0.95} \mathrm{Gd}_{0.05} \mathrm{O}_{1.975}$, averaged over 10 randomly generated structures for each solid solution. 


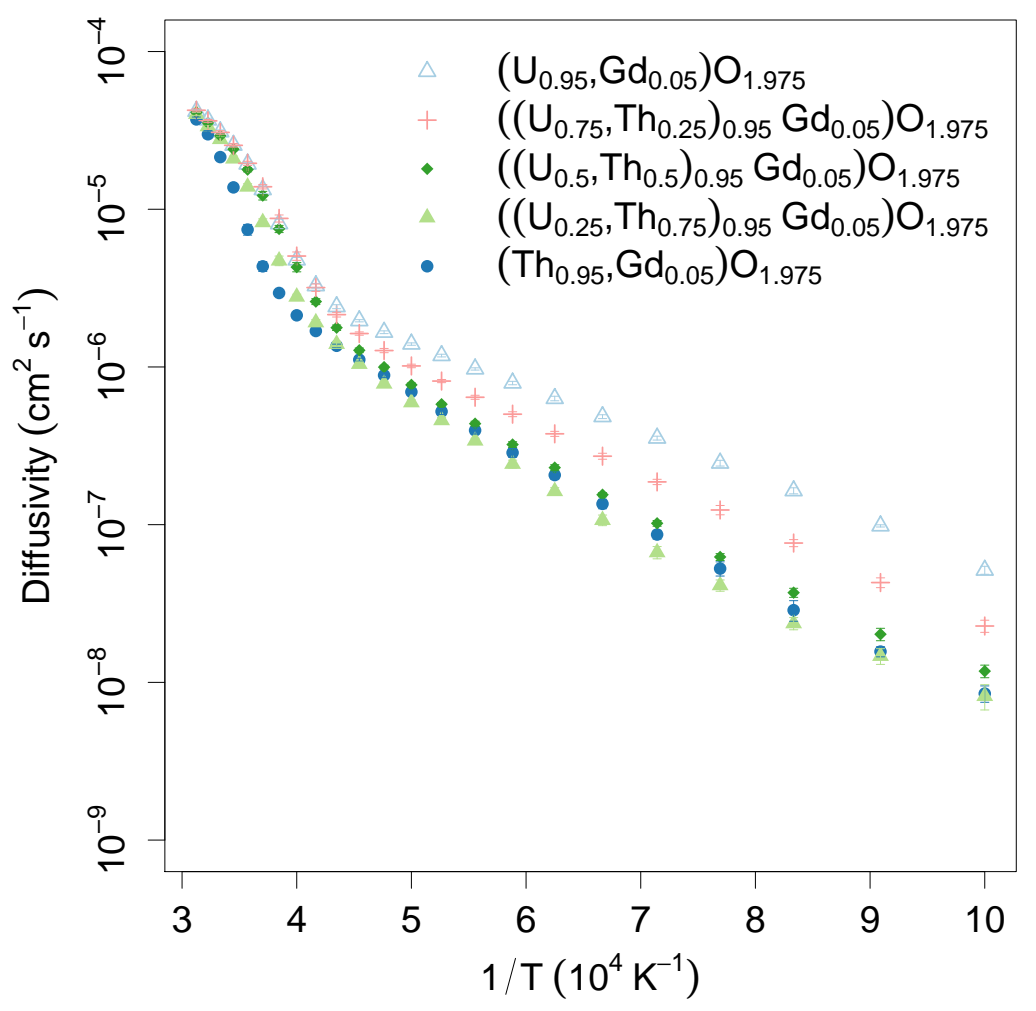

Figure 2: Oxygen diffusivity as a function of temperature for different compositions of $\left(\mathrm{U}_{\mathrm{X}} \mathrm{Th}_{\mathrm{X}-1}\right)_{0.95} \mathrm{Gd}_{0.05} \mathrm{O}_{1.975}$, averaged over 10 randomly generated structures for each solid solution. 


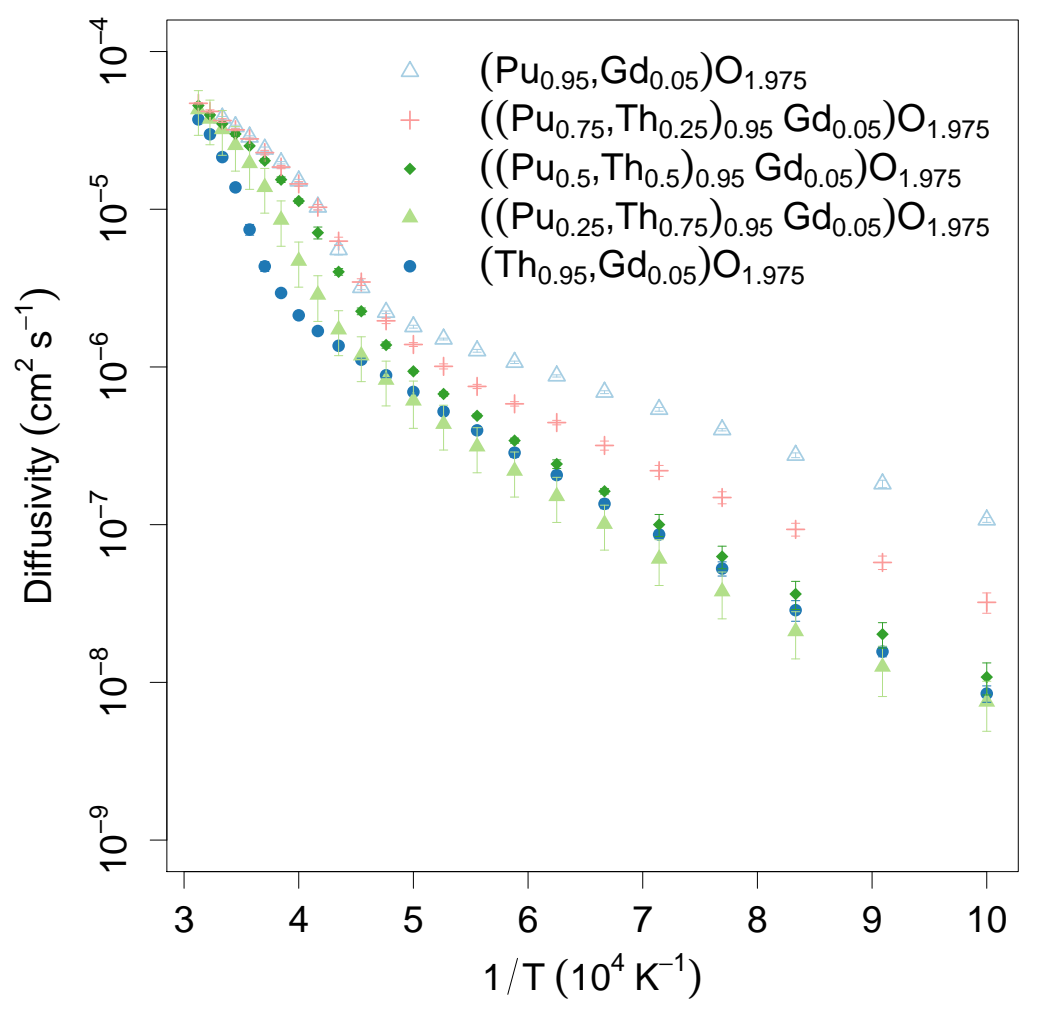

Figure 3: Oxygen diffusivity as a function of temperature for different compositions of $\left(\mathrm{Pu}_{\mathrm{x}} \mathrm{Th}_{\mathrm{x}-1}\right)_{0.95} \mathrm{Gd}_{0.05} \mathrm{O}_{1.975}$, averaged over 10 randomly generated structures for each solid solution. 


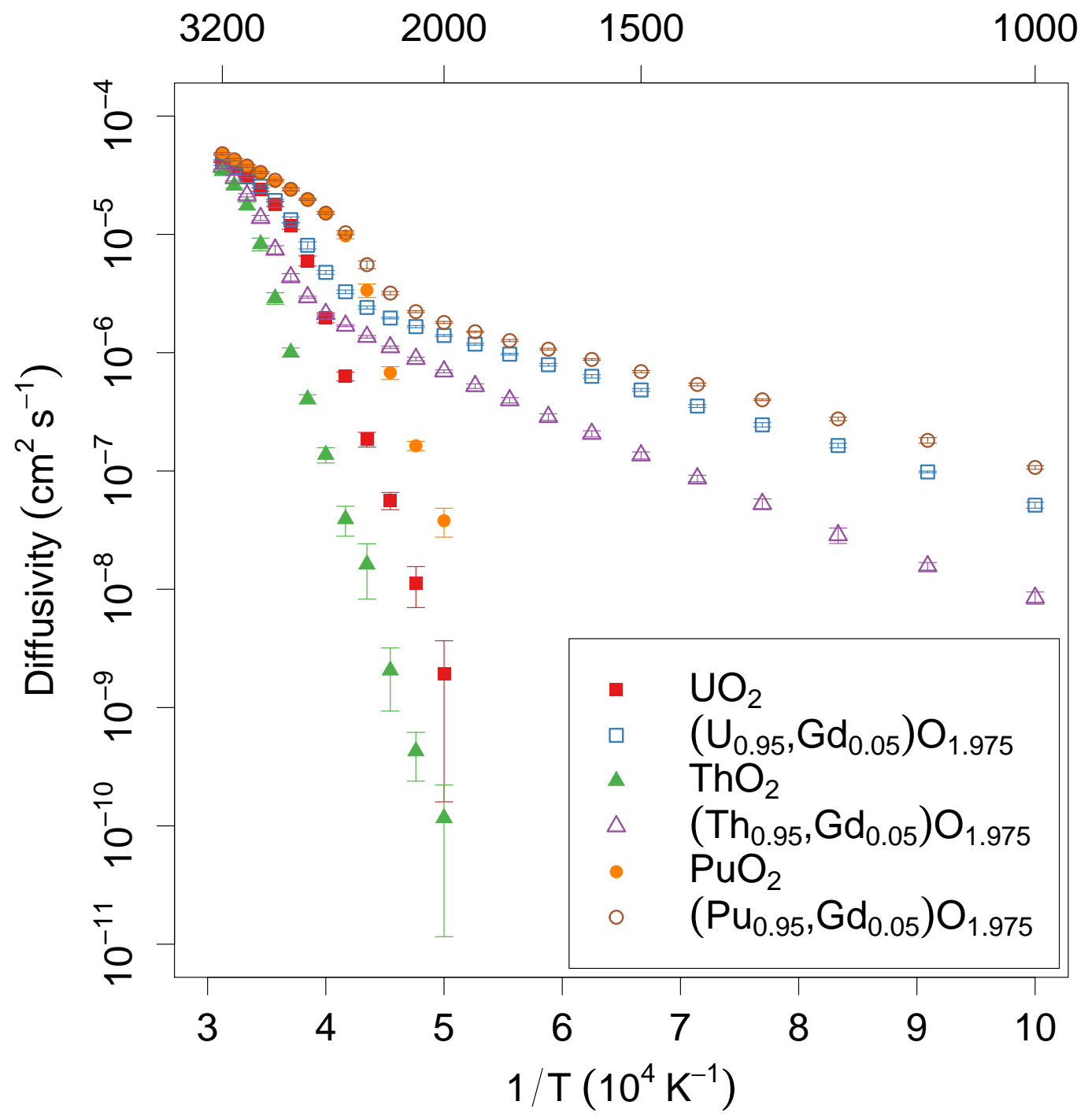

Figure 4: Oxygen diffusivity as a function of temperature for different compositions of $\left(\mathrm{Pu}_{\mathrm{x}} \mathrm{Th} \mathrm{h}_{\mathrm{x}-1}\right) \mathrm{O}_{2}$, $\left(\mathrm{Pu}_{\mathrm{x}} \mathrm{Th}_{\mathrm{x}-1}\right) \mathrm{O}_{2},\left(\mathrm{Pu}_{\mathrm{x}} \mathrm{Th}_{\mathrm{x}-1}\right) \mathrm{O}_{2}$ and the same systems with $5 \%$ of the cation sub-lattice doped with $\mathrm{Gd}$ ions, averaged over 10 randomly generated structures for each solid solution. 


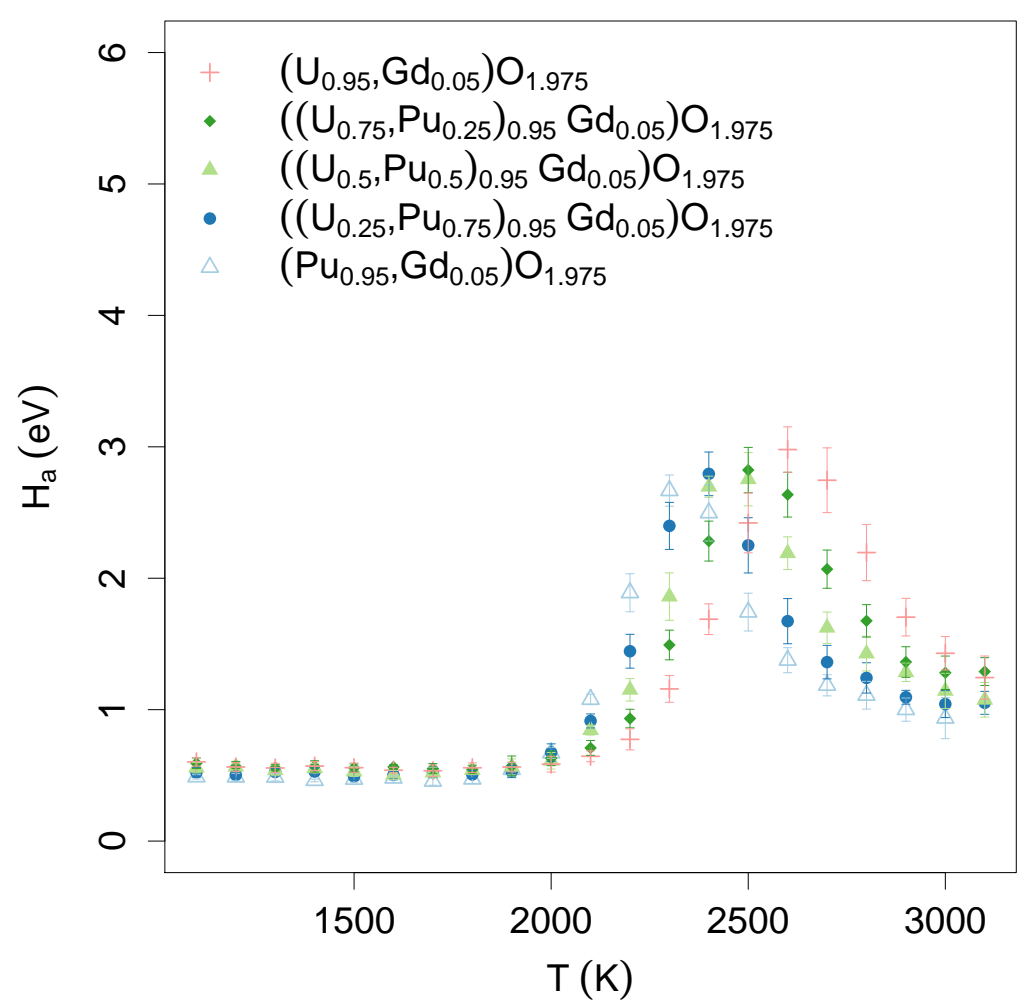

Figure 5: Activation energy, $\mathrm{H}_{\mathrm{a}}$, as a function of temperature for oxygen migration in seven $\left(\mathrm{U}_{\mathrm{X}} \mathrm{Pu} \mathrm{u}_{\mathrm{X}-1}\right)_{0.95} \mathrm{Gd}_{0.05} \mathrm{O}_{1.975}$ compositions each averaged over 10 randomly generated structures. 


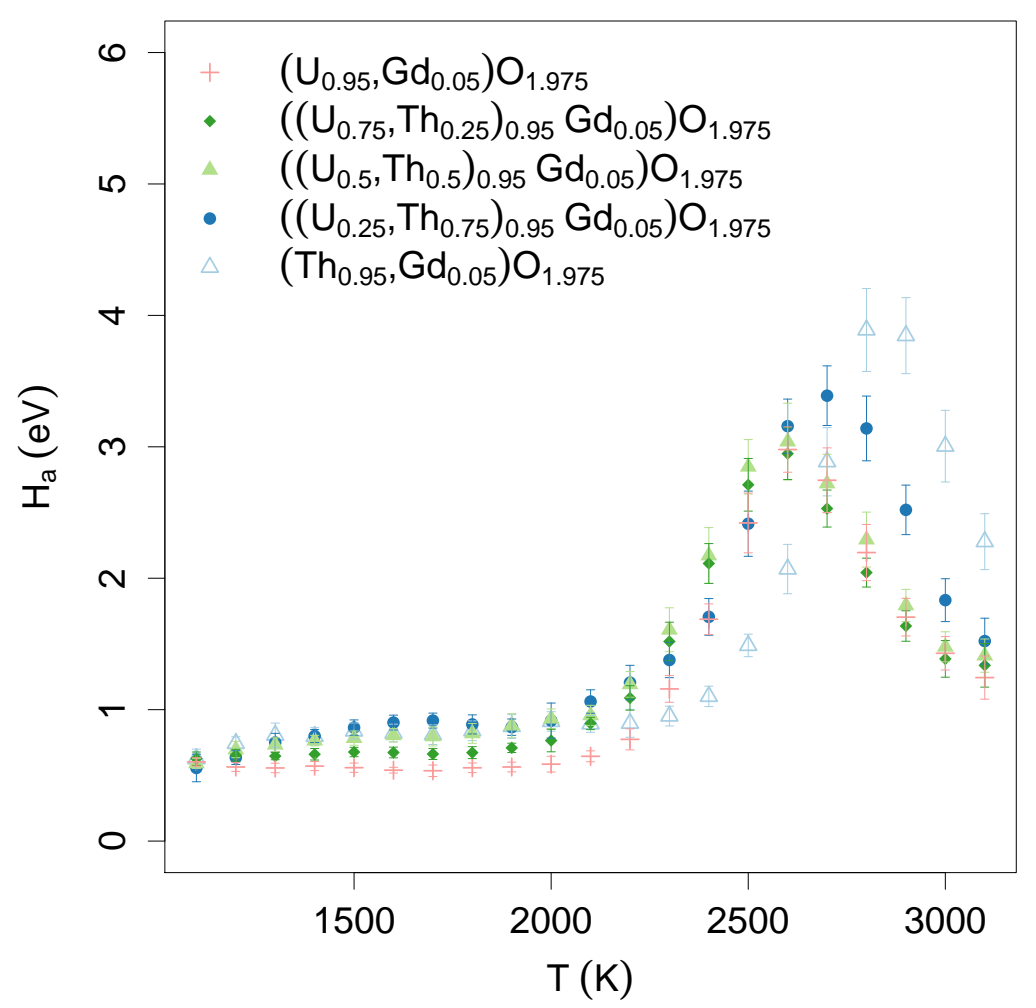

Figure 6: Activation energy, $\mathrm{H}_{\mathrm{a}}$, as a function of temperature for oxygen migration in seven $\left(\mathrm{U}_{\mathrm{x}} \mathrm{Th}_{\mathrm{x}-1}\right)_{0.95} \mathrm{Gd}_{0.05} \mathrm{O}_{1.975}$ compositions each averaged over 10 randomly generated structures. 


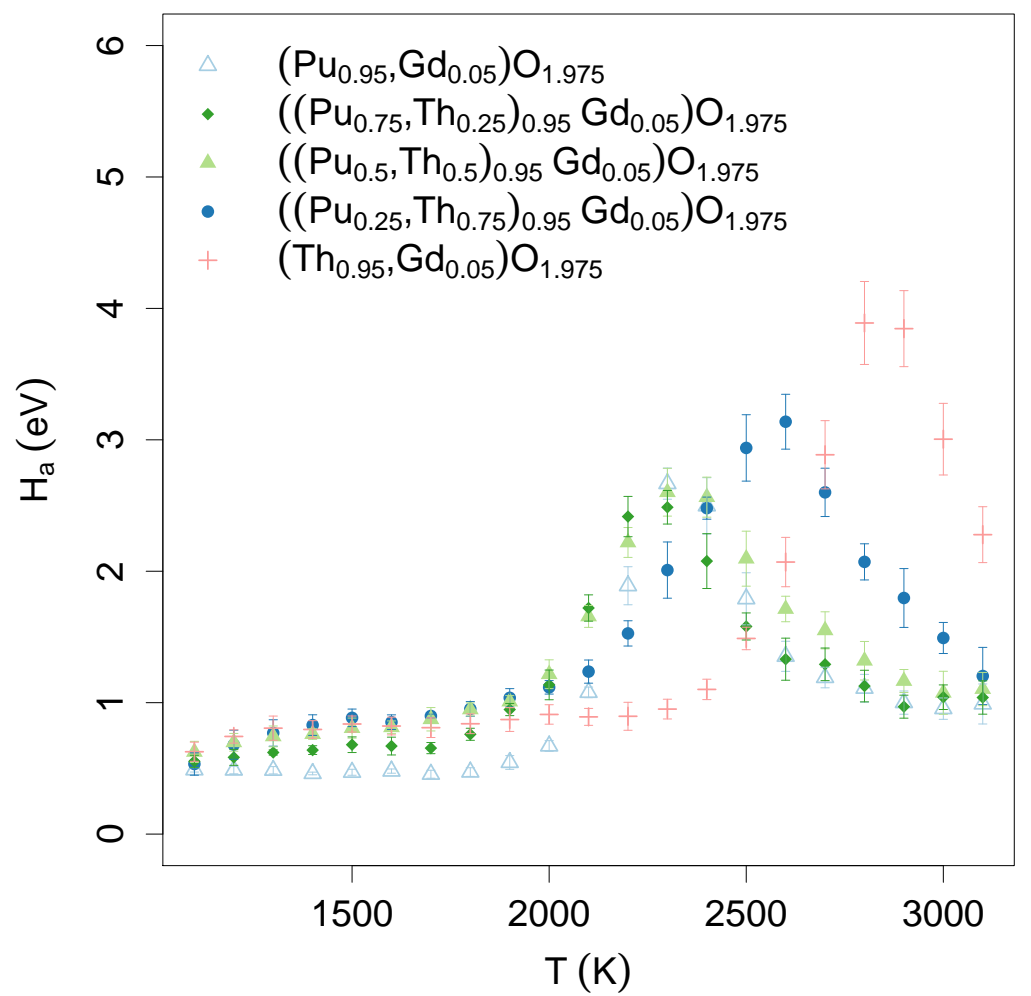

Figure 7: Activation energy, $\mathrm{H}_{\mathrm{a}}$, as a function of temperature for oxygen migration in seven $\left(\mathrm{Pu}_{\mathrm{x}} \mathrm{Th}_{\mathrm{x}-1}\right)_{0.95} \mathrm{Gd}_{0.05} \mathrm{O}_{1.975}$ compositions each averaged over 10 randomly generated structures.

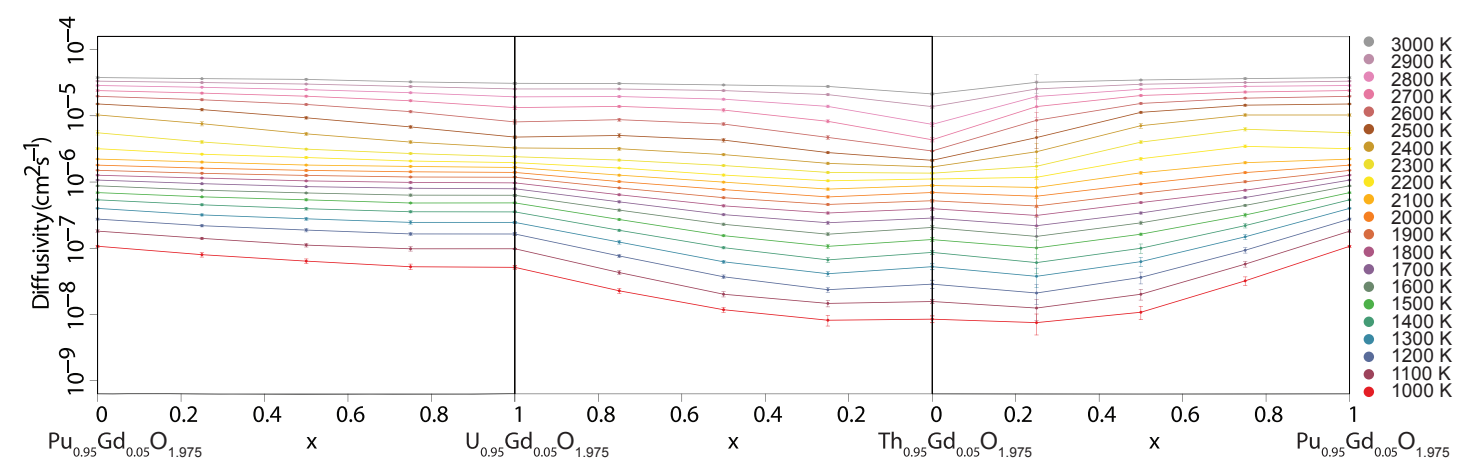

Figure 8: Oxygen diffusivity as a function of composition for $\left(\mathrm{U}_{\mathrm{x}} \mathrm{Pu}_{\mathrm{x}-1}\right)_{0.95} \mathrm{Gd}_{0.05} \mathrm{O}_{1.975}$, $\left(\mathrm{U}_{\mathrm{x}} \mathrm{Th}_{\mathrm{x}-1}\right)_{0.95} \mathrm{Gd}_{0.05} \mathrm{O}_{1.975}$ and $\left(\mathrm{Pu}_{\mathrm{x}} \mathrm{Th}_{\mathrm{x}-1}\right)_{0.95} \mathrm{Gd}_{0.05} \mathrm{O}_{1.975}$ for 10 randomly generated structures, averaged for each composition. The error bars correspond to the standard deviation of the 10 runs. 


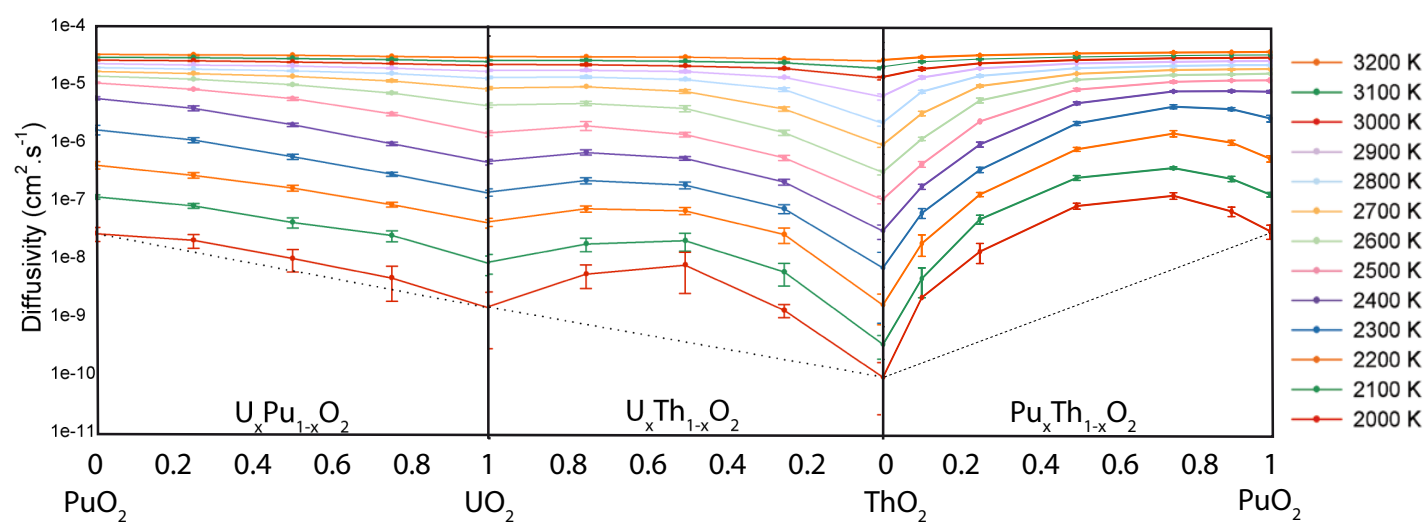

Figure 9: Oxygen diffusivity as a function of composition for $\left(\mathrm{U}_{\mathrm{x}} \mathrm{Pu} \mathrm{u}_{\mathrm{x}-1}\right) \mathrm{O}_{2}, \quad\left(\mathrm{U}_{\mathrm{x}} \mathrm{Th}_{\mathrm{x}-1}\right) \mathrm{O}_{2}$ and $\left(\mathrm{Th}_{\mathrm{X}} \mathrm{Pu}_{\mathrm{x}-1}\right) \mathrm{O}_{2}$ for 10 randomly generated structures, averaged for each composition. [13] 


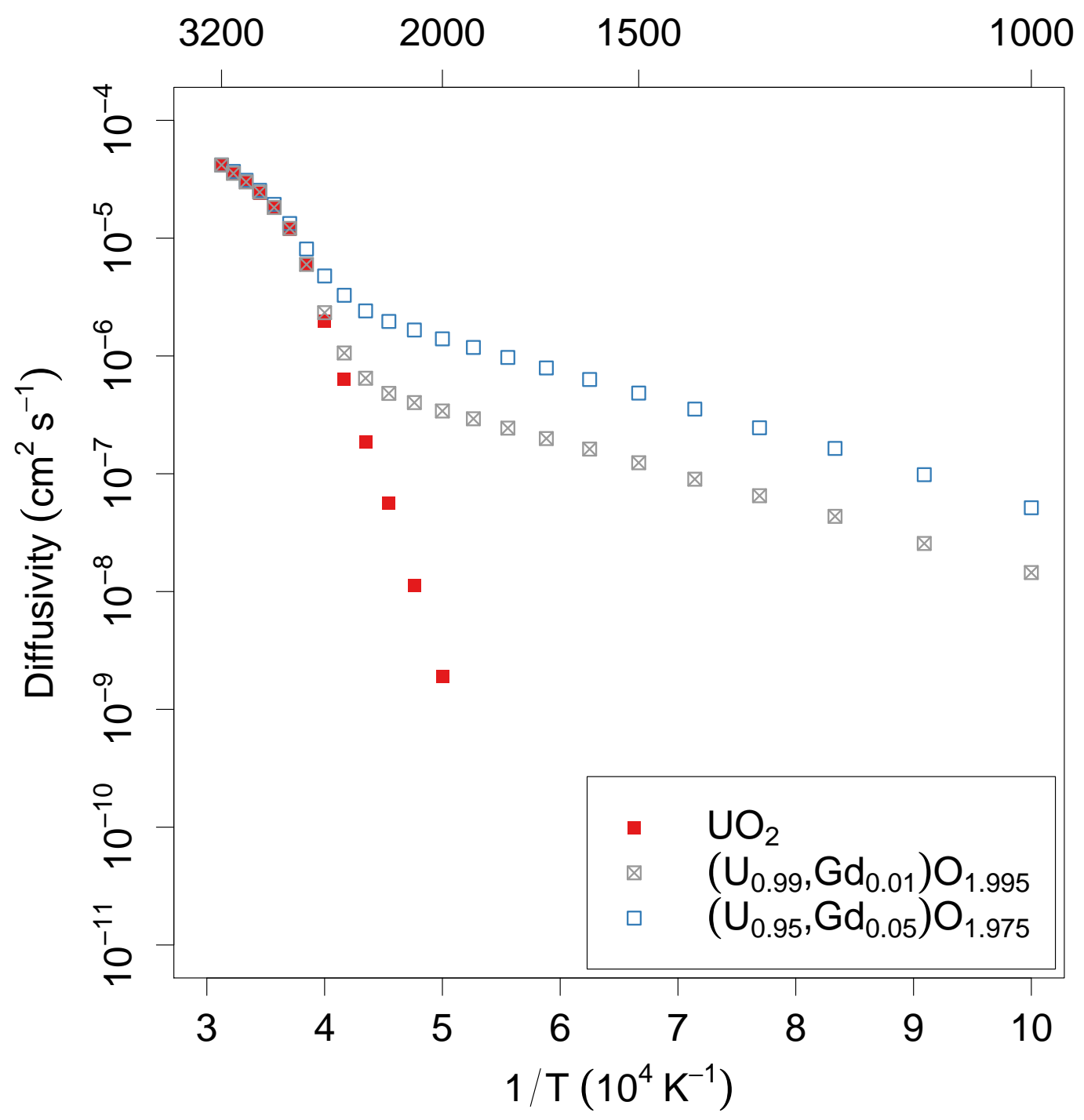

Figure 10: $\mathrm{UO}_{2}$ oxygen diffusivity as a function of temperature for different concentrations of Gd doping. 